\title{
Weak immunogenicity of SARS-CoV-2 vaccine in patients with hematologic malignancies
}

Florent Malard $\circledast^{1,2,7}$, Béatrice Gaugler ${ }^{1,2,7}$, Joel Gozlan ${ }^{2,3,7}$, Lucie Bouquet ${ }^{4}$, Djeneba Fofana ${ }^{3,5}$, Lama Siblany ${ }^{1,2}$, Deborah Eshagh ${ }^{2}$, Olivier Adotevi ${ }^{4}$, Caroline Laheurte ${ }^{4}$, Laure Ricard ${ }^{1,2}$, Rémy Dulery (10 ${ }^{1,2}$, Nicolas Stocker ${ }^{1,2}$, Zoe van de Wyngaert (iD ${ }^{1,2}$, Alexis Genthon ${ }^{1,2}$, Anne Banet ${ }^{1,2}$, Mara Memoli ${ }^{1}$, Souhila Ikhlef ${ }^{1}$, Simona Sestilli ${ }^{1,2}$, Anne Vekhof ${ }^{1}$, Eolia Brissot ${ }^{1,2}$, Zora Marjanovic ${ }^{1}$, Yannick Chantran ${ }^{6}$, Nancy Cuervo ${ }^{3}$, Eric Ballot ${ }^{6}$, Laurence Morand-Joubert ${ }^{3,5}$ and Mohamad Mohty (D) ${ }^{1,2}$

(c) The Author(s) 2021

This study evaluated the safety and immunogenicity of BNT162b2 vaccine in patients with hematological malignancies. Antibodies blocking spike binding to immobilized ACE-2 (NAb) correlated with anti-Spike (S) IgG d42 titers (Spearman $r=0.865, p<0.0001$ ), and an anti-S IgG d42 level $\geq 3100 \mathrm{UA} / \mathrm{mL}$ was predictive of NAb $\geq 30 \%$, the positivity cutoff for NAb $(p<0.0001)$. Only $47 \%$ of the patients achieved an anti-S IgG d42 level $\geq 3100 \mathrm{UA} / \mathrm{mL}$ after the two BNT162b2 inocula, compared to $87 \%$ of healthy controls. In multivariable analysis, male patients, use of B-cell targeting treatment within the last 12 months prior to vaccination, and CD19 ${ }^{+}$ B-cell level $<120 /$ LL, were associated with a significantly decreased probability of achieving a protective anti-S IgG level after the second BNT162b2 inoculum. Finally, using the IFN- $\gamma$ ELISPOT assay, we found a significant increase in T-cell response against the $S$ protein, with $53 \%$ of patients having an anti-S IgG-positive ELISPOT after the second BNT162b2 inoculum. There was a correlation between the anti-S ELISPOT response and IgG d42 level (Spearman $r=0.3026, p=0.012$ ). These findings suggest that vaccination with two BNT162b2 inocula translates into a significant increase in humoral and cellular response in patients with hematological malignancies, but only around half of the patients can likely achieve effective immune protection against COVID-19.

Blood Cancer Journal (2021)11:142; https://doi.org/10.1038/s41408-021-00534-z

\section{INTRODUCTION}

The dismal prognosis after infection by the severe acute respiratory syndrome coronavirus-2 (SARS-CoV-2), called Coronavirus Disease 2019 (COVID-19) in patients with hematologic malignancies is now well established. A meta-analysis, including 3377 adult patients with these diseases, reported a $34 \%$ risk of death in those suffering from COVID-19 [1]. Furthermore, B-cell depleting immunotherapy has been associated with prolonged inhospital stay and higher mortality after COVID19 [2]. Therefore, patients with hematologic malignancies have been prioritized for primary prevention of COVID-19 with vaccination.

Based on randomized phase III clinical trials, several COVID-19 vaccines became available in late 2020, early 2021, with the BNT162b2 (Pfizer/BioNTech), ChAdOx1 nCoV-19 (Oxford/AstraZeneca), and mRNA-1273 (Moderna) vaccines being available in Europe and in the United States of America [3-5]. Nevertheless, people with hematologic malignancies were not included in those vaccine clinical trials. Hematologic malignancies are often associated with immunosuppression, and the treatment used can further worsen immune defect, raising the question of vaccine immunogenicity in those patients. In particular, antiCD20 monoclonal antibodies used in lymphoid malignancies and other B-cell targeting treatment such as drugs used in multiple myeloma, including proteasome inhibitors, immunomodulatory drugs, anti-CD38 monoclonal antibodies, or steroids, may impair SARS-CoV-2 neutralizing antibody production after vaccination. Similarly, hematopoietic cell transplantation $(\mathrm{HCT})$ is associated with a profound immune defect of both $B$ and $T$ cells [6], which raises the question of vaccine immunogenicity in those patients. In fact, it was recently reported in patients with chronic inflammatory disease that glucocorticoids and B-cell depleting agents substantially impair immunogenicity of mRNA vaccines to COVID19 [7].

In patients with hematologic malignancies, preliminary studies reported a low seroconversion rate after the first BNT162b2 inoculum in patients, ranging from 18 to $25 \%[8,9]$. These findings compare poorly with the results of a phase 1 mRNA vaccine immunogenicity trial that reported robust antibody responses after two injections of $30 \mu \mathrm{g}$ of BNT162b2 in essentially $100 \%$ of healthy volunteers [10]. Therefore, it appears indispensable to evaluate the global vaccine immunogenicity in patients with hematologic malignancies, to determine the factors associated with the immune response and to decipher the mechanism underlying the lack of response in some patients, in order to adapt

\footnotetext{
${ }^{1}$ APHP, Hôpital Saint Antoine, Service d'Hématologie Clinique et de Thérapie cellulaire, Paris, France. ${ }^{2}$ Sorbonne Université, INSERM UMR938, Centre de Recherche Saint-Antoine (CRSA), F-75012 Paris, France. ${ }^{3}$ APHP, Hôpital Saint Antoine, Department of Virology, Paris, France. ${ }^{4}$ Department of Medical Oncology, University Hospital of Besançon, INSERM,

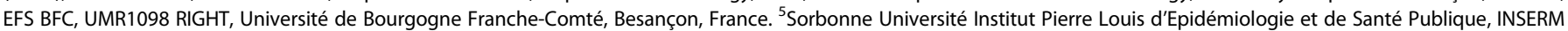
UMR S1136, Paris, France. ${ }^{6}$ APHP, Hôpital Saint Antoine, Service d'Immunologie, Paris, France. ${ }^{7}$ These authors contributed equally: Florent Malard, Béatrice Gaugler, Joel Gozlan. email: florent.malard@inserm.fr
} 
the vaccination strategy. Other key questions are whether, in patients with hematologic malignancies, antibodies from vaccine responders are able to functionally neutralize SARS-CoV- 2 and if the T-cell response against SARS-CoV-2 epitopes is maintained.

With this background, we evaluated the safety and immunogenicity of BNT162b2 vaccine in the first 239 patients with hematologic malignancies vaccinated in our department.

\section{PATIENTS AND METHODS \\ Patients}

From 18 January 2021, patients with a history of allogeneic (allo) HCT and/or an active hematologic malignancy became eligible for COVID-19 vaccination in France. They were initially scheduled to receive two intramuscular injections of $30 \mu \mathrm{g}$ of BNT162b2, 3 weeks apart. Based on the French health authority guidelines, the two injections were finally administered 4 weeks apart in most patients. Retrospective chart review was performed according to institutional guidelines. Written informed consent was obtained in accordance with the principles of the declaration of Helsinki.

\section{Safety assessment}

Side effects after the first and second BNT162b2 injections were reviewed from patients' charts and graded according to the Common Terminology Criteria for Adverse Events (CTCAE v5.0). Patients with symptoms suggesting a possible COVID-19 infection underwent a nasopharyngeal swab testing for SARS-CoV-2.

\section{Serological assessment}

As part of routine monitoring practice, two serological assays were realized, one before the first and second vaccinations, on day 28 , and another one 14 days after the second vaccination (day 42). Immunogenicity was assessed by automated chemiluminescence assay (CMIA), using both the SARS-CoV-2 reagents (Abbott, Rungis, France) for qualitative detection of anti-N IgG (aimed at the SARS-CoV-2 nucleocapside) and the SARS-CoV-2 lgG II Quant (Abbott, Rungis, France) for the quantitative detection of anti-S IgG (aimed at the SARS-CoV-2 spike protein). All dosages were performed on the Alinityl platform (Abbott, Rungis, France), according the manufacturer's recommendations.

We also analyzed routine serological assessments of prioritized health workers who were vaccinated in the same hospital, as a control cohort for patients with hematologic malignancies (although they were mostly older in age) but to facilitate comparison of vaccine immunogenicity.

\section{Neutralization experiments}

A SARS-CoV-2 surrogate neutralization assay, based on antibody-mediated blockade of ACE-2-Spike protein interaction was used, according to the manufacturer's recommendations (ichromax Covid-19 nAB, Boditech, South Corea). Briefly, the SARS-CoV-2 neutralizing antibodies (nABs) present in sera samples were preincubated with a fluorescence-labeled SARS-CoV-2 Spike RBD antigen, in a detection buffer containing ACE-2biotin conjugate. The mixture was then loaded in a lateral flow nitrocellulose matrix where covalent complexes RBD-ACE-2-biotin are immobilized on the streptavidine capture "Test line". The more nAbs is present, the more it interferes with the binding of labeled RBD to ACE-2biotin, which results in less fluorescence signal. A fluorescence inhibition above $30 \%$ is considered as positive. This semi-quantitative assay both correlates with a neutralizing SARS-CoV-2 Ab ELISA assay (Boditech Package insert) and whole-virus neutralization assay in cell culture (Marot et al.; manuscript in preparation).

\section{T-cell response assessment}

IFN- $\gamma$ production was measured on peripheral blood mononuclear cells (PBMC) obtained from excess blood available from routine laboratory tests performed in these patients as part of their standard care, before vaccination and after the second dose, using IFN- $\gamma$ ELISpots kits (Diaclone, France) according to the manufacturers' instructions. After thawing, $3 \times 10^{5}$ PBMC were added to the wells in X-VIVO 15 medium (Lonza, Basel, Switzerland), and stimulated with peptide pools spanning the SARS-CoV-2 spike protein (pool 1 and pool 2) and the receptor binding domain (RBD), membrane protein (VME1), or CEF (CMV, EBV, Influenza virus, MHC class I epitopes) + CEFT (CMV, EBV, Influenza virus, Tetanus toxoid, MHC class II epitopes) as positive controls (PepMix from JPT peptides, final concentration $1 \mu \mathrm{g} / \mathrm{mL}$ ).
Medium containing DMSO was used as the negative control. Assays were performed in duplicate and incubated for $18-20 \mathrm{~h}$ at $37^{\circ} \mathrm{C}$ with $5 \% \mathrm{CO}_{2}$. ELISpot plates were counted using the C.T.L Immunospot system (Cellular Technology Limited, Cleveland, Ohio, United States of America) and assessed with Immunospot 5.0 analyser software. Values were expressed as spot forming cells $/ 10^{6}$ PBMC and calculated after subtraction of values from negative-control wells. T-cell responses were considered as positive when the spot number was $\geq 10$ and ratio 2.5 -fold above background.

\section{Statistical analysis}

The Mann-Whitney nonparametric test was used to compare anti-S IgG level or T-cell responses [receptor binding domain (RBD), entire $S$ protein, VME1 and CEF/CEFT] according to clinical [age, body mass index (BMI), patients' gender, diagnosis and treatment status] or biological $\left(\mathrm{CD} 19^{+} \mathrm{B}\right.$ cells and $\mathrm{CD}^{+} \mathrm{T}$ cells) parameters. The nonparametric Wilcoxon paired test was used to compare anti-S IgG or T-cell response levels at day 0 versus day 42. Correlations between anti-S IgG and $\mathrm{CD} 19^{+} \mathrm{B}$-cell and T-cell responses were computed using nonparametric Spearman correlation. Generalized Maximally Selected Statistics was used to determine the best cutoff point for day 42 anti-S IgG levels that could predict achievement of seroneutralization. Multivariate regression analyses were performed to identify clinical and/or biological parameters associated with humoral and cellular response to BNT162 b2. Statistical analyses were performed with GraphPad Software (GraphPad Prism 9, San Diego, CA) and EZR version 1.27 (Saitama Medical Center, Jichi Medical University), a graphical user interface for R (The R Foundation for Statistical Computing; version 3.1.1).

\section{RESULTS}

\section{Population characteristics}

In total, 239 patients with a hematologic malignancy received their first vaccination between January 18 and March 25, 2021 (Fig. 1), of which, 237 received a second dose 28 days later. One patient was not able to receive the second injection due to contracting COVID-19 in the meantime, and one patient due to disease progression and death from the underlying hematologic malignancy. Thirty-three patients had no serological assessment after the second BNT162b2 inoculum and were not analyzed. Finally, since a history of COVID-19 has been associated with an enhanced response to the COVID-19 vaccine [11], five patients with a medical history of COVID-19 before vaccination and four with no history but positive for anti-N IgG antibodies at baseline were analyzed separately. Overall, we were able to evaluate the immune-efficacy of two injections of BNT162b2 in 195 patients (Table 1). Their median age was 68.9 (range, 21.5-91.7) years. The most common diagnoses were multiple myeloma $(n=52)$ and non-Hodgkin lymphoma $(n=44) ; 136$ patients had a lymphoid and 59 a myeloid malignancy. Most patients had a history of chemotherapy $(n=161,82.6 \%)$ including 67 with ongoing treatment. In addition, 82 patients had a history of HCT or CAR T-cell treatment. Finally, the majority of patients $(n=130,66.7 \%)$ had a history of B-cell depletion treatment, including 57 (29.2\%) who received such treatment at the time of vaccination or within the past 12 months.

\section{BNT162b2 safety and tolerability}

After the first injection, 57.1\% $(n=88)$ of patients developed adverse events, all of them being grade 1-2 (Supplementary Fig. 1, $n=154)$. The most common were injection site pain $(42.9 \%)$, fatigue $(20.1 \%)$, and myalgia (10.4\%). After the second injection of BNT162b2, 34.4\% of patients showed adverse events (grade 1-2, $26 \%$; grade 3, $8.4 \%$; grade $4,0 \%$ ), of the same most common types: injection site pain (grade 1-2, 23.4\%; grade 3,1.9\%), fatigue (grade 1-2, 13\%; grade 3,5.8\%), and myalgia (grade 1-2, 13\%; grade $3,3.9 \%)$.

\section{Serological immune response}

In the 195 patients analyzed, we observed a significant increase of anti-S IgG antibodies between day 28 and day $42(p<0.0001$, 


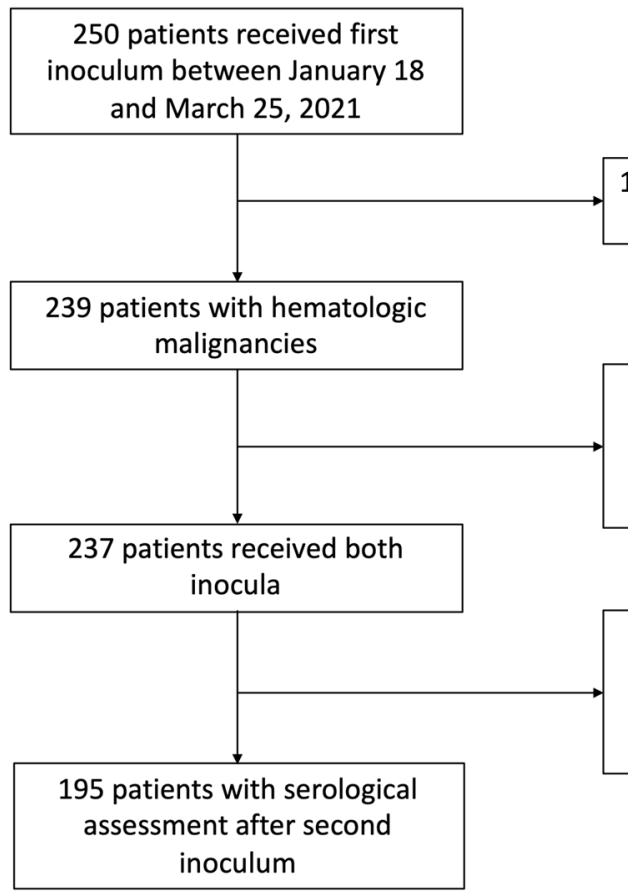

11 patients with non-malignant disease

not analyzed

2 patients ( 1 severe COVID 19 and 1 hematologic relapse after first

inoculum) with no serological assessment available

33 patients with no serological assessment after second inoculum 9 patients with history of COVID19 before first inoculum

inoculum

Fig. 1 Patients' population. Patients with hematological malignancies assessed for response after vaccination with the BNT162b2 vaccine.

Fig. 2A). Nevertheless, compared to healthy controls $(n=30)$, anti-S IgG at day 42 were significantly lower in patients with hematologic malignancies ( $p=0.0002$, Fig. $2 A)$. We, then, sought to assess factors associated with antibody titer. Body mass index and underlying disease had no impact on anti-S IgG at day 42 (Fig. 2B-D). In contrast, male and/or older patients, those with ongoing chemotherapy and those receiving anti-B-cell treatment within the previous 12 months had significantly lower anti-S IgG at day 42 (Fig. 2E-H).

\section{Factors predicting serological immune response and neutralization}

Since $B$ cells are the drivers of serological response, we evaluated the relationship between $\mathrm{CD} 19^{+}$B cells and anti-S IgG at day 28 and day 42. We found strong correlations between the two parameters both on day 28 (Spearman $r=0.613, p<0.0001$; Fig. 3A) and day 42 (Spearman $r=0.677, p<0.0001$; Fig. 3B), indicating that $B$ cells are likely the main driver of immune response after BNT162b2 inoculation. Finally, patients with $B$ cells $<120 / \mu \mathrm{L}$ had a significantly lower anti-S IgG level at day $42(p<$ 0.0001 ; Fig. 3C). Importantly, there was no correlation between anti-S IgG levels at day 42 and total gamma globulin levels, total lymphocyte, $\mathrm{CD}^{+} \mathrm{T}$ cell, $\mathrm{CD} 4^{+} \mathrm{T}$ cell, or $\mathrm{CD}^{+} \mathrm{T}$ cell counts (data not shown).

The threshold for anti-S IgG positivity in being protective against COVID19 has not yet been defined. However, recent evidences have linked the clinical efficacy of immune response to the neutralizing antibody levels in serum of infected or vaccinated patients [12]. Therefore, we evaluated neutralizing antibodies (NAb) in 97 patients using excess serum available from other routine laboratory tests performed in these patients as part of their standard care. We found that NAb correlated with anti-S IgG day-42 titers (Spearman $r=865, p<0.0001$; Fig. 3D). Furthermore, we found that an anti-S lgG day-42 level $\geq 3100 \mathrm{UA} / \mathrm{mL}$ was predictive of a NAb $\geq 30 \%$, the positivity cutoff for NAb ( $p<$ 0.0001 , Supplementary table 1). Therefore, we defined an anti-S lgG day-42 level $\geq 3100 \mathrm{UA} / \mathrm{mL}$ as the threshold for a neutralizing and protective response. In our cohort, only $3 / 195$ patients (1.5\%) achieved this level at day 42 after the first BNT162b2 inoculum and $91 / 196$ (46.7\%) after second inoculum, compared to $26 / 30$ (87\%) of healthy controls.

We then performed a logistic regression to identify in a multivariate analysis, parameters associated with achievement of protective anti-S lgG day-42 level ( $\geq 3100 \mathrm{UA} / \mathrm{mL})$. We found that patients' age ( $\geq 71$ years versus $<71$ years), BMI ( $>25$ versus $\leq 25 \mathrm{~kg}$ / $\left.\mathrm{m}^{2}\right)$, and $\mathrm{CD} 19^{+}$B-cell level $(<120 / \mu \mathrm{L}$ versus $\geq 120 / \mu \mathrm{L})$ had no impact on achievement of a protective anti-S IgG level after two BNT162b2 inoculum. In contrast, male gender and ongoing chemotherapy were associated with a significantly decreased probability of achieving the defined protective anti-S IgG level after two BNT162b2 inoculum [odds ratio (OR) 0.126, 95\% confidence interval (95Cl) $0.022-0.709, p=0.02$; OR $0.146,95 \%$ $\mathrm{Cl} 0.025-0.866, p=0.03$ respectively].

\section{T-cell response}

Finally, we assessed T-cell response in 68 patients with available PBMC at baseline (before first vaccine) and/or after second vaccine dose (day 42), using the ELISPOT assay. We found a significant increase in $\mathrm{T}$-cell response directed against the $\mathrm{S}$ protein (either the RBD or the entire $S$ protein) targeted by the vaccine, while there was no increase against the membrane protein (VME1) or a pool of viral peptides (CMV, EBV, and Flu) used as controls (CEF/ CEFT) (Fig. 4A and Supplementary Fig. 2). Therefore, 53\% of patients $(n=36)$ had a cellular response against the $S$ protein after the second BNT162b2 inoculum.

Next, we sought to assess factors associated with T-cell response. Underlying disease, patient's age, BMI, treatment status, use of antiB-cell treatment within the previous 12 months and $\mathrm{CD}^{+}{ }^{+} \mathrm{T}$ cells had no impact on T-cell response (data not shown), while male gender was associated with a decreased T-cell response $(p=0.098$ for the entire $S$ protein and $p=0.011$ for the RBD, Fig. 4B). Furthermore, there was no correlation between T-cell response against the $S$ protein and the number of the $\mathrm{CD}^{+}, \mathrm{CD}^{+}{ }^{+}$, or $\mathrm{CD} 8^{+}$ $T$ cells (data not shown). However, we observed a correlation with the anti-S IgG day-42 level (Spearman $r=0.3026, p=0.012$ for the entire $S$ protein and spearman $r=0.2648, p=0.029$ for the RBD; Fig. 4C). Interestingly, among the 36 patients with a T-cell response directed against the $S$ protein, 17 did not achieve a protective anti-S 
Table 1. Patients' characteristics.

\begin{tabular}{|c|c|}
\hline Category & $\begin{array}{l}\text { Patients' cohort } \\
N=195\end{array}$ \\
\hline Median age, years (range) & $68.9(21.5-91.7)$ \\
\hline Male & $117(60.0 \%)$ \\
\hline Female & $78(40.0 \%)$ \\
\hline BMI & $24.8(17.8-61.8)$ \\
\hline Lymphoid malignancies & $136(69.7 \%)$ \\
\hline Acute lymphoblastic leukemia & $3(1.5 \%)$ \\
\hline Non-Hodgkin lymphoma & $44(22.6 \%)$ \\
\hline Hodgkin lymphoma & $5(2.6 \%)$ \\
\hline Chronic lymphocytic leukemia & $26(13.3 \%)$ \\
\hline Multiple myeloma & $52(26.7 \%)$ \\
\hline MGUS & $6(3.0 \%)$ \\
\hline Myeloid malignancies & $59(30.3 \%)$ \\
\hline Acute myeloid leukemia & 31 (15.9\%) \\
\hline Myelodysplastic syndrome & $10(5.1 \%)$ \\
\hline Myeloproliferative neoplasm & $18(9.2 \%)$ \\
\hline \multicolumn{2}{|l|}{ Current status } \\
\hline Untreated & $34(17.4 \%)$ \\
\hline Stable disease & $9(4.6 \%)$ \\
\hline Progressive disease & $8(4.1 \%)$ \\
\hline Partial response & $18(9.2 \%)$ \\
\hline Complete response & $127(65.1 \%)$ \\
\hline History of chemotherapy & $161(82.6 \%)$ \\
\hline Previous chemotherapy & $94(48.2 \%)$ \\
\hline Ongoing chemotherapy & $67(34.4 \%)$ \\
\hline History of HCT/cell therapy & $82^{\mathrm{a}}(42.1 \%)$ \\
\hline Autologous HCT & $41(21.0 \%)$ \\
\hline Allogeneic HCT & $41(21.0 \%)$ \\
\hline CAR T-cells & $1(0.5 \%)$ \\
\hline \multicolumn{2}{|l|}{ B-cell-targeted therapy ${ }^{\mathrm{b}}$} \\
\hline Yes & $130(66.7 \%)$ \\
\hline Within the last 12 months & 57 (29.2\%) \\
\hline$>12$ months & $73(37.4 \%)$ \\
\hline Anti-CD20 monoclonal antibody & $54(27.7 \%)$ \\
\hline Venetoclax & $4(2.1 \%)$ \\
\hline Ibrutinib & $3(1.4 \%)$ \\
\hline Cladribine & $2(2.0 \%)$ \\
\hline Campath & $1(0.5 \%)$ \\
\hline Anti-CD19 CAR T-cells & $1(0.5 \%)$ \\
\hline Allo-HCT conditioning regimen & $21(10.8 \%)$ \\
\hline $\begin{array}{l}\text { IMiD/proteasome inhibitor/anti-CD38 } \\
\text { monoclonal antibody }\end{array}$ & $44(22.6 \%)$ \\
\hline
\end{tabular}

$B M I$ is for body mass index, MGUS monoclonal gammopathy of undetermined significance, HCT hematopoietic cell transplantation, IMiD immunomodulatory imide drugs.

${ }^{a}$ One patient received autologous and allogeneic HCT.

${ }^{b}$ Only the latest B-cell targeted therapy is considered.

IgG level ( $\geq 3100 \mathrm{UA} / \mathrm{mL}$ ) after the second BNT162b2 inoculum, including 15 with impaired B-cell status (B-cell lymphopenia, $n=12$ or active CLL $n=3$ ), suggesting that immunity to vaccine was not completely abrogated in these patients. Overall, in patients with evaluable T-cell data, $66 \%$ achieved humoral and/or cellular response after 2 BNT162b2 inocula.
Finally, a logistic regression was performed to identify parameters associated with achievement of a T-cell response against the $S$ protein in a multivariate analysis. We found that treatment status was the only feature associated with the absence of T-cell response (current treatment versus no current treatment, OR $0.175,95 \% \mathrm{Cl} 0.046-0.674, p=0.011$; Table 2).

\section{Response in patients with a history of COVID-19}

The humoral response was also evaluated among the nine patients with a history of COVID-19 who received two BNT162b2 inocula. Six (67\%) achieved a seroprotective level of anti-S IgG at day $42(\geq 3100 \mathrm{UA} / \mathrm{mL})$. Among the nonresponders, one patient received anti-B-cell treatment (rituximab) within the previous 12 months, while the other two patients had not been treated during the same period (one untreated monoclonal gammopathy of undetermined significance and one follicular lymphoma in complete response).

\section{DISCUSSION}

This retrospective study evaluated safety/tolerability and immune response after 2 BNT162b2 inoculations in patients with hematologic malignancies.

The BNT162b2 vaccine was well tolerated. After the first inoculum, no patients developed grade III-IV side effects and injection site pain was the predominant complaint. Interestingly, after the second dose, while the overall incidence of side effects was lower, those of grade III were reported in $8.4 \%$ of the patients, mainly related to a flu-like syndrome (fatigue, myalgia), suggesting that enhanced immune response after the second inoculum directly contributed to the observed side effects. The overall incidence of adverse events in our cohort is comparable to that previously reported in healthy individuals in phase 1 and $2 / 3$ clinical trials $(27-50 \%)[3,10]$ or in real life data $(79 \%)[13]$. However, while very few serious side events were reported in those studies $(0-1.1 \%)[3,10,13]$, the incidence $(8.4 \%)$ of grade 3 adverse events in our series may appear high. Nevertheless, in our patients, none of the grade 3 adverse events required hospitalization, and all recovered with self-administration of acetaminophen. Therefore, our study confirms that the BNT162b2 vaccine is safe in highly immunosuppressed patients with hematologic malignancies, and suggests that preemptive administration of acetaminophen may be recommended after the second inoculum to prevent a severe flu-like syndrome in those patients.

Regarding efficacy, previous studies reported a low seroconversion ranging from 18 to $25 \%$ after the first BNT162b2 inoculum in patients with hematologic malignancies [8, 9]. However, raw serological data are difficult to analyze since the precise threshold of anti-Spike Abs levels conferring a clinical protection and/or an effective neutralizing activity of the sera are still unknown. These correlations likely rely on the population tested as well as the serological assay used [14]. For this reason, we evaluated in our cohort the functional activity of the anti-spike antibodies quantified in routine practice by a surrogate neutralization assay based on blockade of ACE-2 Spike protein interaction. Interestingly, the best anti-spike IgG Abs cutoff level predicting an effective seroneutralization activity was quite high (3100 UA/ml), This level, which is higher than the $50 \mathrm{UA} / \mathrm{ml}$ positive cutoff given by the fabricant (Abbott) to define a positive test, was therefore used in our cohort to define serologic immunity against COVID-19 in our study. Based on this cutoff, the number of patients with seroconversion after the first BNT162b2 inoculum was only $1.5 \%$, which is lower compared to previous reports. Nevertheless, we showed that the anti-S lgG level significantly increased after the second BNT162b2 inoculum, highlighting that a vaccine booster is effective in improving seroconversion in immunosuppressed 

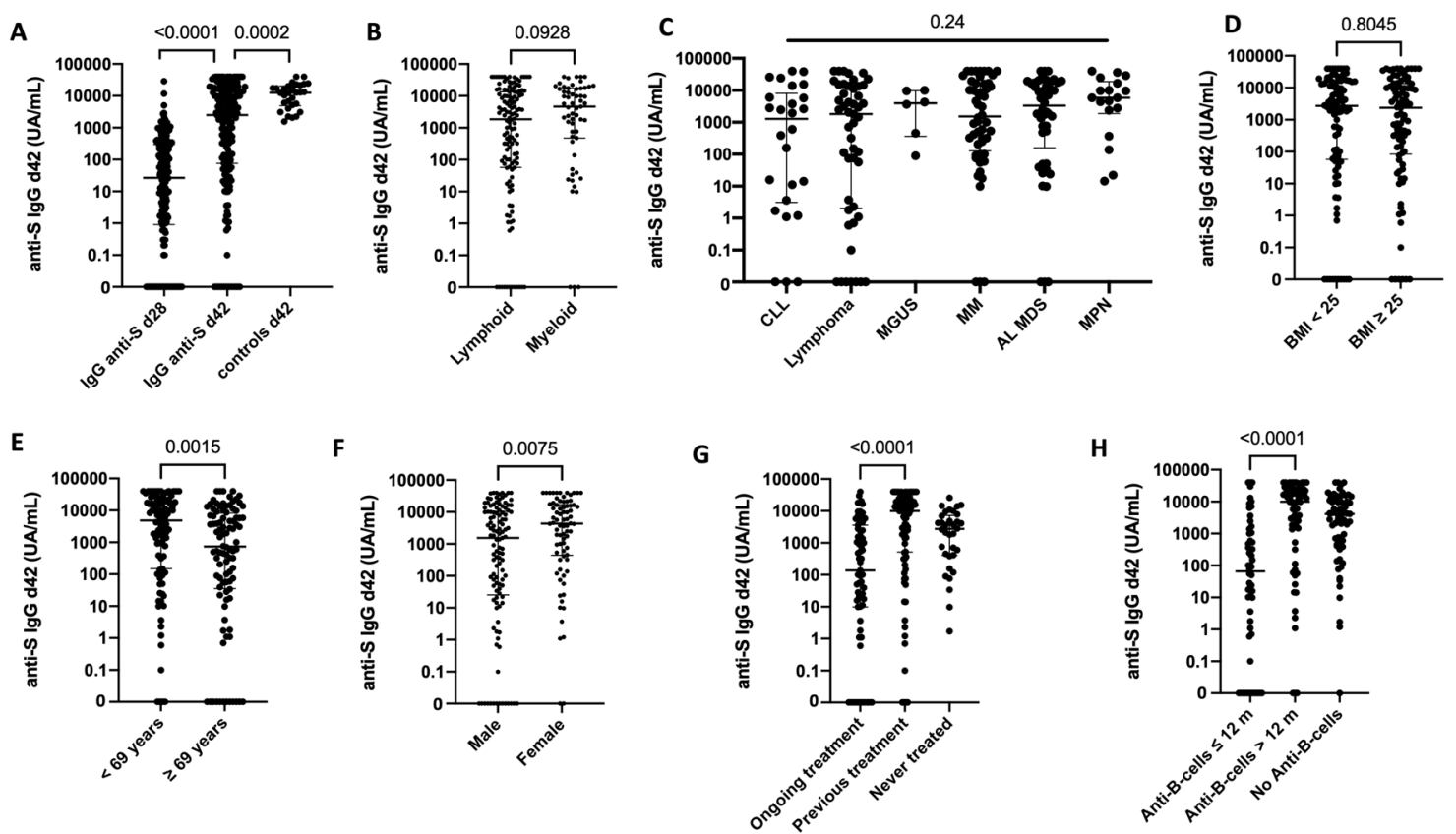

Fig. 2 Serological response to COVID-19 BNT162b2 vaccine. Anti-S IgG antibodies were evaluated before the second BNT162b2 vaccine dose at day 28 (d28) and 2 weeks later at day 42 (d42). A anti-S IgG antibody at d28 and d42 in patients ( $n=195)$ and at d42 in healthy controls $(n=30)$. B-H anti-S lgG antibody at d42 according to disease (B-C), body mass index (D), patients age (E), gender (F), treatment status (G), and use of anti-B-cells treatment $(\mathbf{H})$.
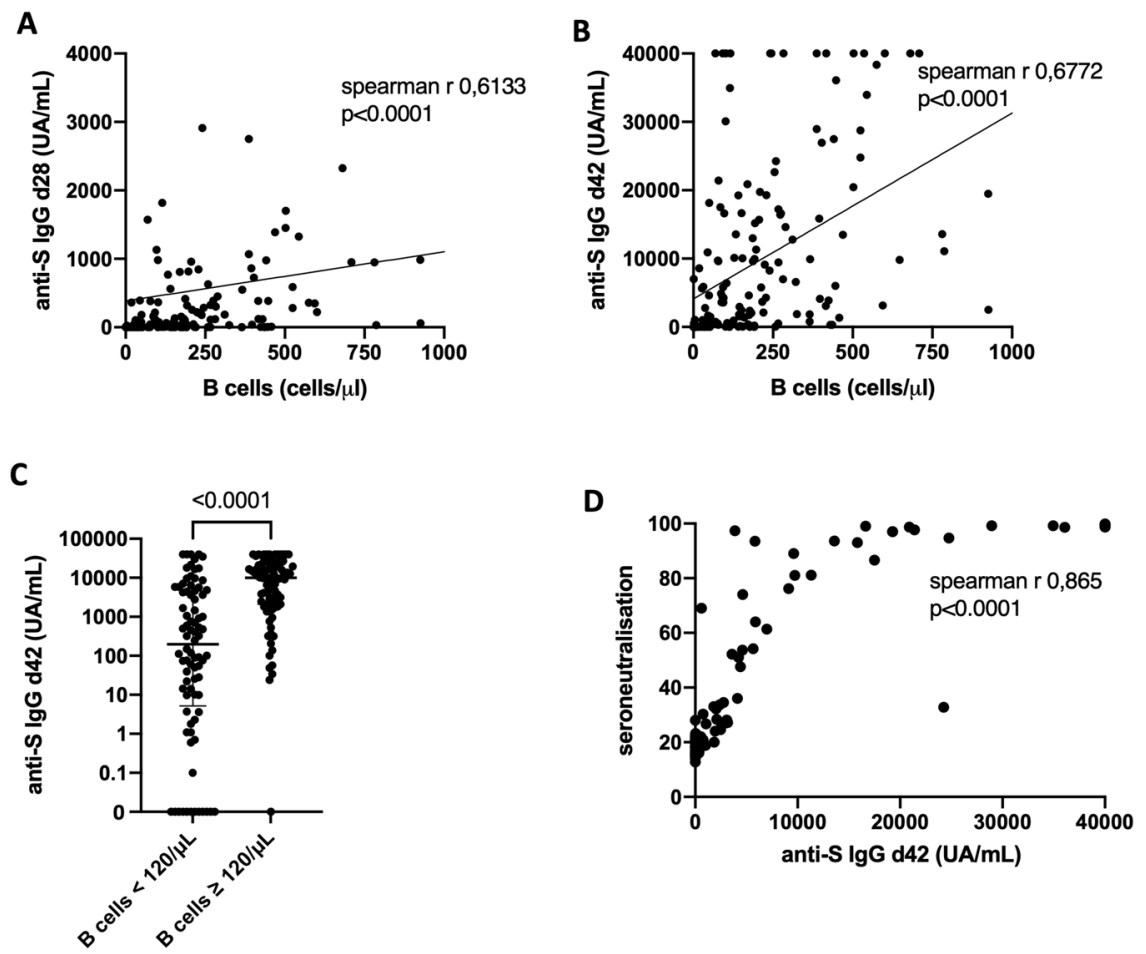

Fig. 3 Correlation between humoral response and B cells and seroneutralization. A, B Correlation between anti-S IgG at d28 (A) and d42 (B) and $\mathrm{CD} 19^{+} \mathrm{B}$ cells $(n=174)$, patients with circulating pathologic B cells (chronic lymphocytic leukemia not in complete remission and some non-Hodgkin lymphoma patients) were excluded from this analysis. C anti-S IgG antibody at d42 according CD19 ${ }^{+}$B-cells level. D Correlation between serum neutralization and anti-S IgG antibodies at d42 $(n=97)$.

patients. In fact, this translated into an increased number of patients with seroconversion after a second BNT162b2 inoculum, reaching $46.7 \%$ of patients. This is in accordance with preliminary data from others reporting that three out of five patients $(60 \%)$ who had received two BNT162b2 inocula were seropositive [8]. We then evaluated in multivariate analysis the factors predicting seropositivity in patients with hematologic malignancies, and found that, while underlying diagnosis and 

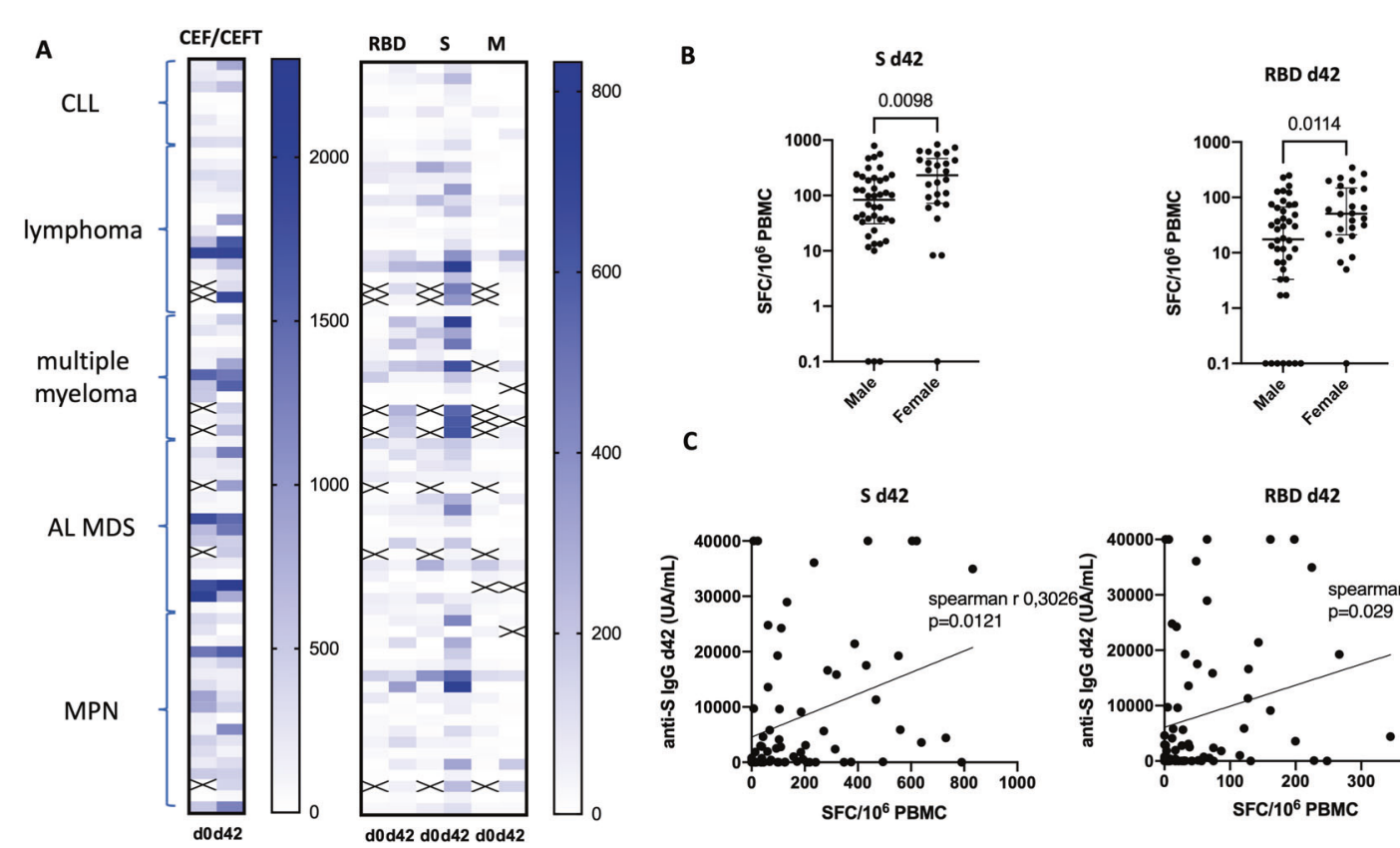

Fig. 4 T-cell response to COVID-19 BNT162b2 vaccine. A T-cell response was assessed by IFN- $\gamma$ ELISPOT at baseline (before first BNT162b2 vaccination, $\mathrm{d0}$ ) and 2 weeks after the second BNT162b2 vaccination (d42), $n=68$. T-cell response against CMV, EBV, Influenza virus, and Tetanus toxoid (CEF/CEFT, left panel). T-cell response against SARS-CoV-2 spike protein (S), or its receptor binding domain (RBD), or against membrane protein (M) (right panel). Cross indicates missing data. CLL chronic lymphocytic leukemia, AL MDS acute leukemia and myelodysplastic syndrome, MPN myeloproliferative neoplasm. B T-cell response against $\mathrm{S}$ and RBD at d42 according to patients' gender. C Correlation between T-cell responses against $\mathrm{S}$ and RBD and anti-S IgG at d42.

Table 2. Multivariate analysis for humoral response and T-cell response.

\begin{tabular}{|c|c|c|}
\hline \multicolumn{3}{|c|}{ Multivariate analysis for humoral response } \\
\hline & Odds ratio $(95 \% \mathrm{Cl})$ & $P$ value \\
\hline Age ( $\geq 69$ years versus $<69$ years) & $0.529(0.244-1.15)$ & 0.11 \\
\hline $\begin{array}{l}\text { Patient gender (male versus } \\
\text { female) }\end{array}$ & $0.343(0.153-0.767)$ & 0.009 \\
\hline BMI ( $>25$ versus $\leq 25 \mathrm{~kg} / \mathrm{m}^{2}$ ) & $1.730(0.803-3.710)$ & 0.16 \\
\hline $\begin{array}{l}\text { Diagnosis (lymphoid versus } \\
\text { myeloid malignancy) }\end{array}$ & $0.765(0.329-1.780)$ & 0.53 \\
\hline Current treatment (yes versus no) & $0.646(0.238-1.750)$ & 0.39 \\
\hline $\begin{array}{l}\text { Anti-B-cell treatment in the } \\
\text { previous } 12 \text { months (yes versus no) }\end{array}$ & $0.231(0.081-0.658)$ & 0.006 \\
\hline $\begin{array}{l}\text { CD19+ B cells }(\geq 120 / \mu \mathrm{L} \text { versus } \\
<120 / \mu \mathrm{L})\end{array}$ & $0.260(0.111-0.609)$ & 0.002 \\
\hline
\end{tabular}

\section{Multivariate analysis for T-cell response}

\begin{tabular}{|c|c|c|}
\hline & Odds ratio $(95 \% \mathrm{Cl})$ & $P$ value \\
\hline Age ( $\geq 69$ years versus $<69$ years) & $0.965(0.313-2.980)$ & 0.95 \\
\hline $\begin{array}{l}\text { Patient gender (male versus } \\
\text { female) }\end{array}$ & $0.476(0.150-1.510)$ & 0.21 \\
\hline BMI ( $>25$ versus $\leq 25 \mathrm{~kg} / \mathrm{m}^{2}$ ) & $1.580(0.542-4.640)$ & 0.40 \\
\hline $\begin{array}{l}\text { Diagnosis (lymphoid versus } \\
\text { myeloid malignancy) }\end{array}$ & $1.240(0.339-4.510)$ & 0.75 \\
\hline Current treatment (yes versus no) & $0.175(0.046-0.674)$ & 0.011 \\
\hline $\begin{array}{l}\text { Anti-B-cells treatment in the } \\
\text { previous } 12 \text { months (yes } \\
\text { versus no) }\end{array}$ & $3.110(0.713-13.500)$ & 0.13 \\
\hline $\begin{array}{l}\mathrm{CD}^{+} \mathrm{T} \text { cells }(\geq 850 / \mu \mathrm{L} \text { versus } \\
<850 / \mu \mathrm{L})\end{array}$ & $2.880(0.889-9.320)$ & 0.078 \\
\hline
\end{tabular}

patients' age had no impact, male gender, use of anti-B-cell targeting treatment within the previous 12 months, and low CD19 ${ }^{+}$B-cell numbers (below the normal threshold) were associated with a failure to achieve seropositivity. Likewise, Herishanu et al. concluded that all CLL patients treated with an anti-CD20 monoclonal antibody in the previous 12 months failed to achieve seroconversion [15]. Similarly, in patients with chronic inflammatory disease, B-cell depleting agents were associated with a significantly reduced humoral response after two BNT162b2 inocula [7]. As to the reduced efficacy of BNT162b2 vaccine on males, no data are available in the setting of COVID19. Nevertheless, it has been reported that adult females develop a much better immune response, with respect to antibody levels, and experienced more severe adverse events following immunization, due to enhanced immune activation, compared to their male counterparts [16].

Humoral immunity is clearly critical for protection against SARS-CoV-2, as evidenced by the correlations on dynamics of neutralizing antibody responses and clinical outcome [17, 18], clinical efficacy of neutralizing Abs levels [12], effectiveness of therapeutic plasma in B-cell depleted patients [19], and of monoclonal antibodies [20]. Nevertheless, cellular immunity also contributes to protection against SARS-CoV-2, and circulating SARS-CoV-2-specific $\mathrm{CD}^{+}$and $\mathrm{CD}^{+}{ }^{+} \mathrm{T}$ cells were identified in $\sim 70 \%$ and $100 \%$ of COVID-19 convalescent patients, respectively [21]. Therefore, in addition to humoral response, we also evaluated T-cell response to BNT162b2 using the ELISPOT assay. We found a significant increase in T-cell response to the $S$ protein after two doses of the BNT162b2 vaccine, but not against the $M$ protein. While the T-cell response correlates with the anti-S IgG level at day 42, some patients with B-cell lymphopenia and no humoral response achieved a T-cell response, indicating that immunity to vaccine was not completely abrogated in these patients and that $\mathrm{T}$-cell response could be protective when humoral immunity is deficient. In fact, a recent study reported the crucial role of $\mathrm{CD}^{+} \mathrm{T}$ cells in 
contributing to the survival of patients with COVID-19 and hematologic cancer, suggesting that CD8 T cells play a key role in limiting SARS-CoV-2, even in the absence of humoral immunity [22]. These data highlight the role of T-cell responses to vaccination by providing protection in patients with hematologic cancer even in the setting of limited humoral responses. Finally, ongoing treatment was the only parameter associated with impaired T-cell response. This suggest that, while it is still mandatory to vaccinate patients under chemotherapy, vaccine response should be assessed at the end of the treatment, and additional BNT162 b2 vaccination should be discussed based on the response.

The strength of this study is the comprehensive evaluation of immune response after 2 BNT162b2 inocula including functional seroneutralization assay and assessment of T-cell response. We were therefore able to accurately evaluate the patients' protective seroconversion against COVID-19 and identify factors predictive of failure. One could suggest that our study lacks an age-matched control group. nevertheless, the aim was to evaluate BNT162b2 vaccine outcomes among patients with hematologic malignancies and to identify factors for poor immune response in this specific population.

Overall, our findings suggest that a second BNT162b2 inoculum translates into a significant increase in humoral response, allowing almost half of the patients to achieve immune protection against COVID-19. Nevertheless, the use of B-cell targeting treatment within the previous 12 months before vaccination, and a low CD19 ${ }^{+}$B-cell level predict failure to achieve immune protection. While some data may suggest delaying COVID-19 vaccination beyond 12 months after use of a B-cell depleting agent and B-cell recovery, health authorities now recommend the administration of a third COVID-19 inoculum in immunosuppressed patients. Given the increase in seroconversion rate between the first and second vaccine injections, evaluation of the effectiveness of such a third inoculum will be imperative.

\section{REFERENCES}

1. Vijenthira A, Gong IY, Fox TA, Booth S, Cook G, Fattizzo B, et al. Outcomes of patients with hematologic malignancies and COVID-19: a systematic review and meta-analysis of 3377 patients. Blood. 2020;136:2881-92.

2. Duléry R, Lamure S, Delord M, Di Blasi R, Chauchet A, Hueso T, et al. Prolonged inhospital stay and higher mortality after Covid-19 among patients with nonHodgkin lymphoma treated with B-cell depleting immunotherapy. Am J Hematol. 2021;96:934-44.

3. Polack FP, Thomas SJ, Kitchin N, Absalon J, Gurtman A, Lockhart S, et al. Safety and efficacy of the BNT162b2 mRNA Covid-19 vaccine. N Engl J Med. 2020;383:2603-15.

4. Ramasamy MN, Minassian AM, Ewer KJ, Flaxman AL, Folegatti PM, Owens DR, et al. Safety and immunogenicity of ChAdOx $1 \mathrm{nCoV}-19$ vaccine administered in a prime-boost regimen in young and old adults (COV002): a single-blind, randomised, controlled, phase $2 / 3$ trial. Lancet (London, England). 2021;396:1979-93.

5. Baden LR, El Sahly HM, Essink B, Kotloff K, Frey S, Novak R, et al. Efficacy and safety of the mRNA-1273 SARS-CoV-2 vaccine. N Engl J Med. 2021;384: 403-16.

6. Ogonek J, Kralj Juric M, Ghimire S, Varanasi PR, Holler E, Greinix H, et al. Immune reconstitution after allogeneic hematopoietic stem cell transplantation. Front Immunol. 2016;7:507.

7. Deepak P, Kim W, Paley MA, Yang M, Carvidi AB, El-Qunni AA, et al. Glucocorticoids and $B$ cell depleting agents substantially impair immunogenicity of mRNA vaccines to SARS-CoV-2. https://www.medrxiv.org/content/10.1101/ 2021.04.05.21254656v2. 2021.

8. Monin L, Laing AG, Muñoz-Ruiz M, McKenzie DR, Del Molino Del Barrio I, Alaguthurai $\mathrm{T}$, et al. Safety and immunogenicity of one versus two doses of the COVID-19 vaccine BNT162b2 for patients with cancer: interim analysis of a prospective observational study. Lancet Oncol. 2021;22:765-78.

9. Terpos E, Trougakos IP, Gavriatopoulou M, Papassotiriou I, Sklirou AD, NtanasisStathopoulos I, et al. Low neutralizing antibody responses against SARS-CoV-2 in elderly myeloma patients after the first BNT162b2 vaccine dose. Blood. 2021;137:3674-6.
10. Walsh EE, Frenck RW Jr, Falsey AR, Kitchin N, Absalon J, Gurtman A, et al. Safety and immunogenicity of two RNA-based Covid-19 vaccine candidates. N Engl J Med. 2020;383:2439-50.

11. Ebinger JE, Fert-Bober J, Printsev I, Wu M, Sun N, Prostko JC, et al. Antibody responses to the BNT162 b2 mRNA vaccine in individuals previously infected with SARS-CoV-2. Nat Med. 2021:27:981-4.

12. Khoury DS, Cromer D, Reynaldi A, Schlub TE, Wheatley AK, Juno JA, et al. Neutralizing antibody levels are highly predictive of immune protection from symptomatic SARS-CoV-2 infection. Nat Med. 2021;27:1205-11.

13. Monin-Aldama $L$, et al. Interim results of the safety and immune-efficacy of 1 versus 2 doses of COVID-19 vaccine BNT162b2 for cancer patients in the context of the UK vaccine priority guidelines. https://www.medrxiv.org/content/10.1101/ 2021.03.17.21253131v1. 2021.

14. Patel EU, Bloch EM, Clarke W, Hsieh YH, Boon D, Eby $Y$, et al. Comparative performance of five commercially available serologic assays to detect antibodies to SARS-CoV-2 and identify individuals with high neutralizing titers. J Clin Microbiol. 2021;59:e02257-02220.

15. Herishanu Y, Avivi I, Aharon A, Shefer G, Levi S, Bronstein Y, et al. Efficacy of the BNT162b2 mRNA COVID-19 vaccine in patients with chronic lymphocytic leukemia. Blood. 2021;137:3165-73.

16. Klein SL, Jedlicka $A$, Pekosz $A$. The $X s$ and $Y$ of immune responses to viral vaccines. Lancet Infect Dis. 2010;10:338-49.

17. Lucas C, Klein J, Sundaram ME, Liu F, Wong P, Silva J, et al. Delayed production of neutralizing antibodies correlates with fatal COVID-19. Nat Med. 2021;27:1309.

18. Dispinseri S, Secchi M, Pirillo MF, Tolazzi M, Borghi M, Brigatti C, et al. Neutralizing antibody responses to SARS-CoV-2 in symptomatic COVID-19 is persistent and critical for survival. Nat Commun. 2021;12:2670.

19. Hueso $T$, Pouderoux $C$, Péré $H$, Beaumont AL, Raillon LA, Ader $F$, et al. Convalescent plasma therapy for B-cell-depleted patients with protracted COVID-19. Blood. 2020;136:2290-5.

20. Gottlieb RL, Nirula A, Chen P, Boscia J, Heller B, Morris J, et al. Effect of bamlanivimab as monotherapy or in combination with etesevimab on viral load in patients with mild to moderate COVID-19: a randomized clinical trial. JAMA. 2021;325:632-44.

21. Grifoni A, Weiskopf D, Ramirez SI, Mateus J, Dan JM, Moderbacher CR, et al. Targets of T cell responses to SARS-CoV-2 coronavirus in humans with COVID-19 disease and unexposed individuals. Cell. 2020;181:1489-501. e1415

22. Bange EM, Han NA, Wileyto P, Kim JY, Gouma S, Robinson J, et al. CD8(+) T cells contribute to survival in patients with COVID-19 and hematologic cancer. Nat Med. 2021:27:1280-9.

\section{ACKNOWLEDGEMENTS}

We acknowledge the Association for Training, Education and Research in Hematology, Immunology and Transplantation for the generous and continuous support of the research work. We thank our nursing staff for their excellent care of our patients, especially Mrs Elisabeth Lambert-Genest and Mrs Sophie Tessier. We would like to thank Mrs Karen Fadel and Mr Frederic De Vassoigne for their technical support. We would like to thank Prof. Junia Melo for (university of Adelaide, Australia) for critical reading of the manuscript.

\section{AUTHOR CONTRIBUTIONS}

FM, BG, and JG share first authorship. FM designed the study, collected, assembled and analyzed data, performed statistical analyses, and wrote and revised the manuscript. BG designed the study, performed experiments, collected, assembled and analyzed data, and helped with writing the manuscript. JG contributed to study design, performed experiments, collected, assembled and analyzed data, and commented on the manuscript. $L S, D E, D F, L B, O A, C L, Y C$, and $E B$ performed experiments and commented on the manuscript. $L R, R D, N S, Z V W, A G, A B$, Mara Memoli, SL, AV, EB, ZM, and NC helped collect data and commented on the manuscript. LMJ helped with analyzing data and commented on the manuscript. Mohamad Mohty designed the study, analyzed data, and helped with writing the manuscript. FM, BG, and Mohamad Mohty have verified the underlying data.

\section{COMPETING INTERESTS}

FM reports lecture honoraria from Therakos/Mallinckrodt, Janssen, Biocodex, Sanofi, JAZZ pharmaceuticals and Astellas, all outside the submitted work. Mohamad Mohty reports grants and lecture honoraria from Janssen, Sanofi, and JAZZ pharmaceuticals, lecture honoraria from Celgene, Amgen, BMS, Takeda, and Pfizer, and grants from Roche, all outside the submitted work. The other authors declare no competing interests. 


\section{ADDITIONAL INFORMATION}

Supplementary information The online version contains supplementary material available at https://doi.org/10.1038/s41408-021-00534-z.

Correspondence and requests for materials should be addressed to F.M.

Reprints and permission information is available at http://www.nature.com/ reprints

Publisher's note Springer Nature remains neutral with regard to jurisdictional claims in published maps and institutional affiliations.
Open Access This article is licensed under a Creative Commons Attribution 4.0 International License, which permits use, sharing, adaptation, distribution and reproduction in any medium or format, as long as you give appropriate credit to the original author(s) and the source, provide a link to the Creative Commons license, and indicate if changes were made. The images or other third party material in this article are included in the article's Creative Commons license, unless indicated otherwise in a credit line to the material. If material is not included in the article's Creative Commons license and your intended use is not permitted by statutory regulation or exceeds the permitted use, you will need to obtain permission directly from the copyright holder. To view a copy of this license, visit http://creativecommons.org/licenses/by/4.0/.

(c) The Author(s) 2021 